\title{
A química dos alimentos como tema gerador para o ensino de ácidos e bases
}

\author{
Food chemistry as a generator theme for teaching acids and bases \\ La química de los alimentos como tema generativo para la enseñanza de ácidos y bases
}

Recebido: 09/07/2021 | Revisado: 17/07/2021 | Aceito: 28/12/2021 | Publicado: 06/01/2022

Amanda Marques de Lima
ORCID: https://orcid.org/0000-0003-0813-8218
Universidade Federal de Pernambuco, Brasil
E-mail: amanda.aml002@ gmail.com
Gerlan Lino dos Santos
ORCID: https://orcid.org/0000-0003-2736-726X
Universidade Federal de Campina Grande, Brasil
E-mail: gerlanlinopjp@ gmail.com
Silvânia Narielly Araújo Lima
ORCID: https://orcid.org/0000-0001-5688-8422
Universidade Federal de Campina Grande, Brasil
E-mail: silvania.narielly@ estudante.ufcg.edu.br
Bruna Gerlane Marques Florentino
ORCID: https://orcid.org/0000-0003-4749-6392
Universidade Federal de Campina Grande, Brasil
E-mail: brunagerlany16@ gmail.com
Fernanda Raquel Dantas
ORCID: https://orcid.org/0000-0001-5656-3812
Universidade Federal de Campina Grande, Brasil
E-mail: fernandaraquel61 @ gmail.com
Aline dos Santos Silva
ORCID: https://orcid.org/0000-0001-5730-2681
ECI José Rolderick de Oliveira, Brasil
E-mail: alinne_2012@ @live.com
Marciano Henrique de Lucena Neto
ORCID: https://orcid.org/0000-0002-1326-7949
Universidade Federal de Campina Grande, Brasil
E-mail: marcianohln@ gmail.com

\section{Resumo}

A química é uma ciência que precisa de contextualização para despertar o interesse dos alunos e promover uma aprendizagem significativa. Além disso, essa ciência tem um importante papel na nossa alimentação, pois está presente nos nutrientes, nas vitaminas, nas gorduras, etc., por isso, o estudo das propriedades dos alimentos que ingerimos diariamente é essencial. Este trabalho tem por objetivo estimular o ensino da química por meio da contextualização, visando o estudo da química dos alimentos como tema gerador para o assunto de ácidos e bases, e conscientizar os alunos à mudança de hábitos alimentares. A pesquisa foi desenvolvida em uma turma de $9^{\circ}$ ano do ensino fundamental de uma escola pública situada em Nova Floresta- PB, por meio de duas aulas teóricas e uma prática, de 45 minutos cada, e pela aplicação de um questionário. Diante dos resultados obtidos, percebeu-se a importância de relacionar a química ao cotidiano dos alunos, pois isso gera uma visão mais ampla nos discentes sobre a teoria abordada e os auxilia a encontrar soluções em situações cotidianas. Também se percebeu a importância e necessidade da realização de mais aulas práticas. A intervenção foi satisfatória e as propostas foram alcançadas com sucesso, sendo notório que os alunos compreenderam a importância e os conceitos do estudo sobre ácidos e bases com a abordagem dos alimentos.

Palavras-chave: Química dos alimentos; Ácidos e bases; Contextualização; Ensino; Experimentação.

\begin{abstract}
Chemistry is a science that needs contextualization to arouse students' interest and promote meaningful learning. In addition, this science has an important role in our diet, as it is present in nutrients, vitamins, fats, etc., so it is essential to study the properties of the food we eat daily. Thus, this work aims to encourage the teaching of chemistry through contextualization, aiming at the study of food chemistry as a generative theme for the subject of acids and bases, and to make students aware of changing eating habits. The research was developed in a 9th grade class of elementary school at a public school located in Nova Floresta-PB, through two theoretical and practical classes and the application of a questionnaire. Given the results obtained, the importance of relating chemistry to the daily lives of students was perceived, as this generates a broader view of the theory in the students and helps them find solutions in everyday situations. It was also noticed the importance and need for more practical classes. The intervention was
\end{abstract}


satisfactory and the proposals were successfully achieved, it being clear that the students understood the importance and concepts of the study of acids and bases with the food approach.

Keywords: Food chemistry; Acids and bases; Contextualization; Teaching; Experimenting.

\section{Resumen}

La química es una ciencia que necesita contextualización para despertar el interés de los estudiantes y promover un aprendizaje significativo. Además, esta ciencia tiene un papel importante en nuestra dieta, ya que está presente en nutrientes, vitaminas, grasas, etc., por lo que es fundamental estudiar las propiedades de los alimentos que ingerimos a diario. Así, este trabajo tiene como objetivo fomentar la enseñanza de la química a través de la contextualización, con el objetivo de estudiar la química de los alimentos como tema generativo de la asignatura de ácidos y bases, y sensibilizar a los estudiantes sobre los cambios en los hábitos alimentarios. La investigación se desarrolló en una clase de noveno grado de la escuela primaria de una escuela pública ubicada en Nova Floresta-PB, a través de dos clases teóricas y prácticas y la aplicación de un cuestionario. Dados los resultados obtenidos, se percibió la importancia de relacionar la química con la vida cotidiana de los estudiantes, ya que esto genera una visión más amplia de la teoría en los estudiantes y les ayuda a encontrar soluciones en situaciones cotidianas. También se percibió la importancia y necesidad de realizar más clases prácticas. La intervención fue satisfactoria y las propuestas se lograron con éxito, quedando claro que los estudiantes entendieron la importancia y conceptos del estudio de ácidos y bases con el enfoque alimentario.

Palabras clave: Química de los alimentos; Ácidos y bases; Contextualización; Enseñanza de la química; Experimentación.

\section{Introdução}

Conforme a hipótese da teoria de aprendizagem significativa de Ausubel (1968, p. 58), a aprendizagem é uma ação cognitiva, de pensamento e de significação. Dessa forma, o processo pedagógico deve partir do conhecimento prévio dos alunos e da associação desses conhecimentos com o cotidiano, para que os estudantes sejam capazes tanto de compreender significativamente os conteúdos quanto de identificar e solucionar possíveis problemas no seu dia a dia (Wartha et al., 2013, p. 87). Assim, ao levar os conteúdos contextualizadamente, o aluno terá mais interesse e curiosidade em aprender, e essa aprendizagem terá um significado para ele, pois, os conteúdos deixam de ser abstratos e são algo presente na sua vida (Almeida et al., 2020).

Se o aluno não conhece o propósito de compreender algum conteúdo abordado e não consegue relacioná-lo com suas próprias necessidades, dificilmente poderá realizar aquilo que o estudo envolve em profundidade (Santos, 2008, p.60). Ou seja, para que o aluno consiga assimilar os conteúdos e se apropriar dos saberes que os circulam, é preciso que estes assuntos sejam abordados interessantemente e faça sentido para a sua vida e realidade. Não conseguindo relacionar os conceitos estudados com a sua vida e encontrar um significado para compreendê-los, o discente terá uma aprendizagem superficial ao invés de uma aprendizagem profunda (Bigolin, 2020, p.8).

A utilização de temas geradores para introduzir os conteúdos científicos é uma excelente forma de relacionar os conceitos com o cotidiano. Os temas geradores são, nesse sentido, estratégias metodológicas que permitem a conscientização da realidade, servindo também para o processo de codificação-decodificação e problematização da situação (Tozoni-Reis, 2006, p.3). Este tema abrange diversos assuntos e problemas vividos pela comunidade ao redor, envolvendo também uma análise, apreensão da realidade e um diálogo com os estudantes, a fim conhecer a realidade social, as percepções e visões da realidade (Costa \& Pinheiro, 2013, p. 43). Ao abordar temas geradores, o docente também pode deixar suas aulas mais interativas e dinâmicas, permitindo a realização de metodologias ativas (Silva et al., 2020).

O ensino de Química, em particular, demanda a relação de dois componentes básicos: a informação Química e o contexto social e do dia a dia (Santos \& Schnetzler, 2003, p. 93). O entendimento dos conteúdos Químicos atrelado ao contexto social auxilia os alunos na formação de cidadãos críticos, informados e capazes de atuar na sociedade. A forma descontextualizada, como o ensino de ciências é normalmente exercido nas escolas, faz com que muitos dos conceitos 
científicos se transformem em palavreados tomados como meros ornamentos culturais repetidos pelos alunos sem qualquer significação cultural (Santos, 2007; Del Pino \& Frison, 2011, p. 41).

A utilização de temas geradores no Ensino de Química tem demonstrado, portanto, ser muito eficiente na facilitação do aprendizado, pois permite a consciência crítica e da cidadania entre os estudantes, além de poder, facilitar a compreensão dos alunos sobre as temáticas, promovendo também uma contextualização dos conteúdos (Silva; Martins; Silva, 2020). Lima et al. (2021) investigaram a contextualização no ensino da Química Orgânica, abordando a química dos perfumes, e perceberam que ao contextualizar os conteúdos houve um grau de interesse e interação maior por partes dos discentes do que nas aulas realizadas apenas expositivamente, sem nenhuma assimilação com o cotidiano. Ou seja, a inclusão de temas geradores provoca o interesse dos discentes além de contribuir para expandir a química para o dia-a-dia dos alunos. Dessa forma, aprender significativamente indica que o discente participa ativamente no processo de ensino-aprendizagem, possibilitando a aquisição de conhecimentos de modo que não esteja fundamentada na repetição ou na cópia dos conteúdos apresentados, mas que seja produto de uma reelaboração pessoal (Santos, 2011; Liell et al., p.60).

De acordo com Guimarães (2009, p. 198), a parte experimental, em conjunto com a contextualização no ensino das ciências, pode gerar nos alunos um estímulo para questionamentos acerca do que está sendo estudado em sala. Desse modo, o assunto a ser estudado é caracterizado como resposta ao contexto criado para os discentes, deixando-os familiarizados e induzindo-os às suas próprias respostas. Zanon e Freitas (2007, p. 94) também corroboram com a ideia de que a atividade experimental deve ser desenvolvida, sob orientação do professor, a partir de questões investigativas que tenham consonância com aspectos da vida dos alunos e que se constituam em problemas reais e desafiadores. É neste sentido que a utilização de estratégias baseadas em atividades práticas ou experimentais têm também sido uma alternativa didática eficiente para o processo ensino-aprendizagem, visto que oferecem uma visão prática do que é estudado teoricamente (Berton et al., 2020; Queiroz et al., 2019; dos Santos \& Menezes, 2020). Desta forma, a química se constitui em um valioso instrumento educativo para a formação de cidadãos, habilitando-os a tomar decisões e participar da resolução de problemas no seu dia a dia.

Um conteúdo que gera grandes dificuldades por parte dos alunos em entender os conceitos pertinentes é o de ácidos e bases. Essa dificuldade pode muitas vezes ser fruto das metodologias utilizadas pelo professor, a qual dificilmente consegue correlacionar tais conteúdos com o cotidiano e com aspectos culturais dos alunos. Como relata Figueira et al. (2009, p.1), os estudantes ainda apresentaram uma ideia superficial e "decorada" dos conceitos sobre os ácidos e bases, não os correlacionando com suas vidas. Em uma pesquisa realizada por Figueira (2010) perguntou-se a alguns alunos de ensino fundamental, médio e superior, qual era o papel das substâncias básicas e ácidas para suas vidas. Porém, muitos deles responderam erroneamente ou não souberam relacioná-las com o seu cotidiano. Devido aos alunos não conseguirem ver algum sentido para estudar os conceitos, muitas vezes os conteúdos de ácidos e bases são julgados como de difícil compreensão, dificultando, assim, o processo de ensino-aprendizagem e a motivação dos alunos. Dessa forma, ao abordar essa temática é necessário que o professor utilize algumas ferramentas pedagógicas e metodológicas, de modo a facilitar a abordagem do conteúdo e a compreensão dos alunos.

Todavia, para organizar um eficiente programa de ensino de Química é necessário identificar situações de alta vivência dos alunos para que, sobre elas, possam formar o seu pensamento Químico (Maldaner, 2000, p. 71). Uma das orientações dos documentos oficiais para o ensino fundamental e médio é a articulação do conhecimento Químico com temas cotidianos, por exemplo, os alimentos (Brasil, 2006, p. 117). Por isso, tendo em vista que a Química tem um importante papel na nossa alimentação, pois está presente nos nutrientes, nas vitaminas, nas gorduras, etc., (Nelson \& Cox, 2005), e que os alimentos estão presentes no dia a dia de todos, sendo também uma cultura de cada região/estado, a utilização desse tema pode ser interessante para ser abordado em sala de aula como um tema gerador e para contextualização de algum conceito Químico. 
Conforme Lima e Barbosa (2015, p. 35), o estudo da Química associado aos alimentos pode ser considerado fundamental para a formação cidadã dos estudantes do ensino fundamental e médio.

Como cada alimento tem sua característica particular devido a sua composição Química e seus diferentes grupos funcionais, eles podem apresentar pH ácido ou básico (Ribeiro \& Seravalli, 2007, p.64). Por isso, dependendo do pH dos alimentos que consumimos, podemos ser acarretados por inúmeras doenças do corpo na saúde física e até emocional, as quais podemos citar a gastrite, obesidade, halitose, enxaqueca, etc. (Gava, 2009, p. 134-140). Para sabermos o que estamos comendo e se aquele alimento fará ou não bem a nossa saúde, vê-se, então, o quanto é importante o conhecimento químico. Além disso, por meio da contextualização dos alimentos com o tema de ácidos e base, os alunos podem conseguir compreender tanto esses conceitos mais significativamente quanto a composição química dos alimentos e de refletir a respeito de seus hábitos alimentares sob a ótica da ciência.

A utilização de indicadores ácido-base natural, como o de repolho-roxo, é uma proposta que vem ganhando destaque no ensino de Química, por ser de fácil acesso e baixo custo, o que possibilita a realização de aulas experimentais e a contextualização de conteúdo (Almeida et al., 2020; Da Silva et al., 2019). Devido às mudanças claras na coloração, esse experimento também pode ser considerado uma forma lúdica para o ensino.

Desenvolver metodologias para amenizar o impacto no sistema educacional provocado por esse período atípico é de extrema importância para o progresso da educação, visto que os temas geradores também podem ser utilizados no ensino remoto (Hodges et. al., 2020), contribuindo para a elucidação dos conteúdos com a realidade dos discentes. Gonçalves (2021) fez uma proposta de aula experimental para o ensino à distância na disciplina de Bioquímica, com o intuito de identificar proteínas em alimentos do cotidiano, e relatou que essa abordagem facilitou o processo norteador do ensino e aprendizagem, aumentando a motivação dos alunos para estudar a disciplina. Assim, vê-se que utilizar experimentos envolvendo alimentos, bem como experimentos, geralmente facilita o processo de ensino-aprendizagem não apenas nas aulas presenciais, mas também nas aulas remotas.

Nessa perspectiva, o objetivo deste trabalho é estimular o ensino da química por meio da contextualização dos conteúdos, visando o estudo da química dos alimentos como tema gerador para o assunto de ácidos e bases, e conscientizar os alunos do ensino fundamental às mudanças de hábitos alimentares. Essa pesquisa foi realizada presencialmente no ano de 2019, porém, pode ter suficiente impacto e relevância para ser abordada no ensino remoto. Para proporcionar uma aprendizagem eficiente, procurou-se também problematizar e abordar os conteúdos através de diferentes metodologias de ensino, dentre elas estão: aulas expositivas dialogadas; aula experimental; análise quantitativa dos dados.

\section{Metodologia}

A presente pesquisa foi desenvolvida no ano de 2019, em uma escola pública situada na cidade de Nova Floresta, interior da Paraíba, presencialmente, com um total de 20 alunos de uma turma do $9^{\circ}$ ano do ensino fundamental. Para a realização dessa pesquisa houve o consentimento do corpo administrativo e pedagógico da escola, especialmente da professora de Química responsável pela turma. Inicialmente, foram realizados os primeiros contatos do nosso grupo de pesquisa com a comunidade local e escolar, de modo a conhecer um pouco sobre a realidade da escola e propor uma parceria de trabalho colaborativo. A turma estava começando a estudar o tema de ácido e bases, porém, estavam apresentando dificuldades em entender o conteúdo. Assim, fez-se uma explanação de um tema gerador que poderia ser útil para facilitar o entendimento da turma sobre essa temática e, após conhecer o ambiente e a turma, propôs-se, com a professora, que utilizar a química dos alimentos como tema gerador poderia ser útil para que os alunos pudessem entender melhor a química dos ácidos e bases.

Esse artigo tem um caráter qualitativo, onde se analisou o comportamento da turma, realizaram-se observações e perguntas durante as aulas, bem como um caráter quantitativo, onde se aplicou um questionário e fez-se a análise dos dados, 
para contribuir com o observado na análise qualitativa. Bogdan e Biklen (1994) e Miranda et al., (2017) destacam a importância da pesquisa qualitativa, pois ela possui como fonte direta de dados o ambiente natural, onde os pesquisadores mergulham no mundo dos sujeitos observados, tentando compreender seu comportamento e como constroem a realidade que atuam. Por outro lado, a abordagem quantitativa potencializa a investigação e permite ao pesquisador uma melhor compreensão do que foi investigado, possibilitando novas interpretações, análises mais detalhadas e a construção de novos conhecimentos sobre a problemática de interesse, além de permitir analisar os dados investigados através de inferências, comparações e analogias, que só são possíveis com o uso dessa abordagem (Do Nascimento \& Cavalcante, 2018).

Em suma, a pesquisa foi realizada em três momentos: o primeiro momento ocorreu com a apresentação da temática e dos objetivos do artigo e com a aplicação de duas aulas teóricas de 45 minutos cada; o segundo pela realização de uma prática experimental; e o terceiro com a aplicação de um questionário.

No primeiro momento, foi feito uma apresentação da pesquisa para a turma se familiarizar e entender os objetivos da pesquisa, abrindo uma discussão para observar os conhecimentos prévios da turma sobre os ácidos, as bases e sobre seus hábitos alimentares. Apesar de a turma já ter iniciado os estudos sobre ácidos e bases, procurou-se abordar os conceitos mais fundamentais dessa teórica, realizando-se uma aula teórica, apresentando conceitos básicos sobre ácidos e bases de Arrhenius, Brönsted-Lowry e Lewis e introduzindo os conceitos de $\mathrm{pH}$ e faixa de $\mathrm{pH}$. Posteriormente, iniciou-se uma segunda aula teórica com uma problematização do conteúdo de ácidos e bases, utilizando a química dos alimentos como um tema gerador, onde se fez perguntas referentes aos alimentos e hábitos alimentares da turma. Logo após, discutiu-se sobre a acidez e basicidades de alguns alimentos mais consumidos mundialmente e também regionalmente, como a tapioca e a macaxeira, mostrando também a faixa de pH em que eles se encontravam, além de discutir sobre os benefícios e malefícios da ingestão de alimentos ácidos e/ou básicos.

No dia posterior às aulas teóricas, levou-se a turma ao laboratório de química da escola para a realização de uma aula experimental, também de 45 minutos, que visou utilizar um experimento com materiais de baixo custo para utilizar a química dos alimentos como tema gerador para o ensino de ácidos e bases. Esse experimento teve como intuito identificar o pH de diferentes alimentos e sucos, utilizando um indicador natural de repolho-roxo. Preferiu-se utilizar apenas a teoria de ácidos e bases de Lewis para explicar todo o experimento, com o intuito de facilitar a compreensão dos alunos.

Para a realização do experimento, a turma preparou, inicialmente, o indicador natural, levando algumas folhas de repolho roxo ao fogo em uma bacia contendo $1 \mathrm{~L}$ de água previamente aquecida. Após as folhas do repolho ficarem brancas, elas foram tiradas do fogo para filtrar o suco formado pelo seu extrato, estando pronto, assim, o indicador natural. Posteriormente, enumerou-se 5 copos e adicionou-se a cada um deles uma substância, sendo elas: suco de laranja, goiaba e limão, leite e vinagre. Em seguida, anotou-se a coloração de cada uma das substâncias e adicionou-se o extrato do repolho aos copos, anotando a coloração que elas adquiriram posteriormente. Em seguida, cada grupo identificou o pH das substâncias através da faixa de $\mathrm{pH}$ do indicador de repolho roxo e realizou-se uma discussão com eles. Durante a abordagem experimental, realizou-se uma análise do comportamento da turma, realizaram-se questionamentos e investigou-se a compreensão dos alunos sobre a temática e sobre o experimento. Vale ressaltar também os alunos foram supervisionados durante todo o experimento, para que nenhum acidente acontecesse.

Por fim, realizou-se uma análise quantitativa, onde se aplicou um questionário diagnóstico para analisar se os alunos conseguiram compreender o que foi apresentado na aula teórica e experimental e na discussão na sala de aula, além de observar se houve uma mudança de paradigma e conscientização quanto a forma de alimentação de cada um. O questionário continha cinco perguntas abertas, para que os alunos pudessem se sentir à vontade em respondê-las a partir das suas concepções e aprendizados adquiridos durante as abordagens realizadas. 


\section{Resultados e Discussão}

Durante a discussão inicial com a turma perceberam-se certas dificuldades por parte dos alunos em diferenciar substâncias ácidas das básicas. Além disso, eles relataram ter muitos hábitos alimentares prejudiciais à saúde, por exemplo, tomar muito refrigerante, comer comidas industrializadas, não comer verduras ou legumes. Durante esses relatos, também foi perguntado se eles sabiam quais desses alimentos citados eram ácidos ou básicos e quais eles julgam que devemos ou não consumir, porém, a maioria não conseguiu responder corretamente.

Alguns alunos também relataram que não se deve consumir nenhum alimento ácido, pois todos eles fazem mal à saúde. Porém, a nossa dieta não deve restringir-se apenas a alimentos básicos (Brasil, 2016, p.13), pois algumas substâncias presentes nos alimentos ácidos conferem muitos benefícios à saúde. É necessário, todavia, um equilíbrio entre o consumo de alimentos ácidos e básicos, pois uma dieta saudável não pode restringir-se apenas a um desses tipos de substâncias. Por exemplo, o ácido linolênico, também conhecido como ômega 3, é uma gordura poli-insaturada que não é produzida pelo organismo, portanto, deve ser obtida a partir da alimentação (Brasil, 2016, p.58). Diante do exposto, é possível perceber a necessidade de uma discussão mais abrangente com esses alunos de ensino fundamental sobre os hábitos alimentares.

De acordo com Astolfi e Develay (2011, p.34), toda a aprendizagem vem interferir num já existente conceito que, mesmo não sendo verdade para a ciência, serve para o docente como uma forma de explicação eficaz das representações dos alunos. Vê-se, então, o quanto é importante conhecer as concepções prévias dos estudantes ao utilizar alguma abordagem metodológica, iniciar algum conteúdo e, principalmente, sobre essa temática dos alimentos, dos ácidos e das bases. Os conhecimentos prévios tornam possível a aquisição de ideias que podem ser utilizadas no universo das categorizações de novas situações, bem como serve de pontos de ancoragem e descobertas de novos conhecimentos (Brum \& Silva, 2014, p. 45).

No início da primeira aula teórica, perceberam-se dificuldades por parte dos alunos em compreender os conceitos de ácido e bases de Arrhenius, bem como diferenciar esses conceitos com os propostos por Brönsted-Lowry e Lewis. Consequentemente, as explicações do que é um pH e a faixa de pH também foram dificultadas. Porém, no decorrer da aula, observou-se que eles começaram a se familiarizar com os conceitos, compreendendo melhor e a conseguindo diferenciar um ácido de uma base pela faixa de pH, mas com alguns erros e limitações. A teoria que eles melhor compreenderam foi a de Lewis. Dessa forma, percebe-se que o aluno necessita do incentivo do processo a despertar os interesses para a aprendizagem da química de forma contextualizada, pois, assim, o cotidiano de cada aluno será melhor entendido, resultando em um maior entrosamento, curiosidade e vontade de aprender, podendo tornar-se uma disciplina compreensiva e interessante, visando seus verdadeiros conceitos (Coelho \& de Lima, 2020).

$\mathrm{Na}$ segunda aula, quando se começou a relacionar a faixa de $\mathrm{pH}$ com os alimentos, os alunos demonstraram estar mais interessados no tema, respondendo sempre às perguntas que eram feitas. Ao mostrar as imagens e o pH ácido de alguns alimentos comuns na alimentação do dia a dia e os mais utilizados na cultura regional dos alunos participante do trabalho, muitos discentes ficaram impressionados, pois, devido ao gosto característico eles achavam que eram totalmente diferentes, como, por exemplo, o feijão, o leite, o queijo, a tapioca, os pães e bolos e, principalmente, o chocolate, o açúcar e o refrigerante. Ademais, eles também ficaram muito interessados e mostraram-se participativos quando se explicou que algumas frutas ácidas, como o limão, a laranja e o abacaxi, quando ingeridas tornam-se alcalinos no organismo, por isso, são consideradas frutas alcalinizantes.

Posteriormente, ao discutir como esses alimentos podem influenciar na saúde e no pH do sangue, os alunos interagiram entre si e com os professores, fazendo perguntas e relatando alguns casos de doenças relacionadas à alimentação de alguns familiares e conhecidos. Como relata Boavida (2016) a maioria das pessoas, principalmente as crianças e adolescentes, ainda desconhece a importância do equilíbrio do pH para a sua saúde e muito menos as consequências que o desequilíbrio ácido-base pode acarretar ao sangue. Por exemplo, ao ingerirmos muitos alimentos ácidos podem ocorrer uma diminuição do 
pH do sangue, levando ao enfraquecimento do sistema imunológico e propiciando um ambiente favorável a proliferação de vírus e bactérias (Stern \& Emmett, 2011). Por isso, essa contextualização foi de suma importância para conscientizar a turma sobre a necessidade de uma dieta equilibrada, facilitando significativamente também o processo de ensino-aprendizagem e a explicação dos conceitos químicos sobre ácidos e bases.

Todavia, conforme o educador Paulo Freire (1996, p.24), para compreender a teoria é preciso experienciá-la. Por isso, além da contextualização dos conteúdos, a utilização da teoria e da prática em aulas de Química é de suma importância para a aquisição de novos conhecimentos, pois facilita a fixação do conteúdo a ela relacionados (Capeletto, 1999, p. 224). Para facilitar o processo de ensino-aprendizagem, a turma foi, então, levada para o laboratório da escola para a realização do experimento intitulado "Repolho Roxo: Indicador ácido-base" (Figura 1).

Nessa aula experimental, pediu-se que os alunos anotassem as colorações das substâncias antes e depois da adição do indicador de repolho roxo e o pH que eles supunham que cada uma delas tinha. Pediu-se também para que eles compartilhassem com as suas observações com toda a turma. Durante esse compartilhamento de informações, notou-se que a maioria dos alunos conseguiu relacionar corretamente a acidez e basicidade das substâncias analisadas sem estar com a faixa de $\mathrm{pH}$ do repolho roxo em mãos. Em seguida, foi mostrado a faixa de $\mathrm{pH}$ do repolho roxo para eles poderem analisar o verdadeiro pH das substâncias estudadas e comparar com as primeiras observações feitas, as quais mostraram-se bastante de acordo. Assim, a turma conseguiu diferenciar corretamente as colorações das soluções a seu devido pH.

Figura 1: Realização do experimento intitulado "Repolho Roxo: Indicador ácido-base".

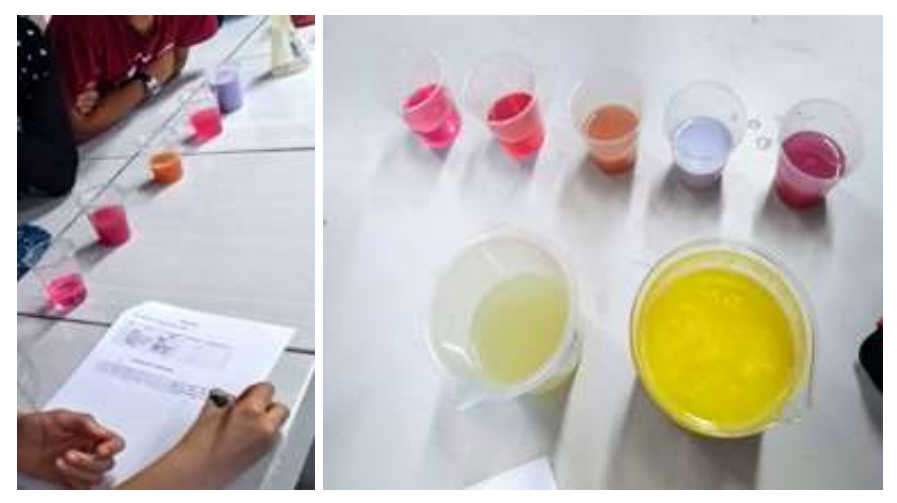

Fonte: Dados da pesquisa (2021).

Durante toda a experimentação, os alunos mostraram-se atentos e prestaram atenção em cada mudança na coloração das soluções, interagindo sempre uns com os outros e com os professores. Vários discentes também relataram que iriam realizar esse experimento em casa com alguns alimentos que eles comem no dia a dia, com o intuito de saber se são ácidos ou bases. Da Silva, da Silva e Viana (2019) realizaram um experimento utilizando o indicador de repolho roxo para analisar o $\mathrm{pH}$ de alguns produtos, como a água sanitária, sabão em pó, o bicarbonato de sódio e o detergente, com o intuito de ensinar os conceitos de ácidos e bases. Esses autores observaram que a experimentação contribuiu significativamente com o desenvolvimento cognitivo dos estudantes, visto que conseguiu tomar a atenção dos estudantes e fez com que os mesmos saíssem de sua zona de conforto e passassem a investigar a basicidade e acidez dos materiais presentes no seu cotidiano.

Após essas abordagens, realizou-se a aplicação de um questionário para analisar quantitativamente se os alunos haviam compreendido a temática abordada. A primeira e a segunda pergunta do questionário tinham o intuito de analisar se após as intervenções os alunos conseguiam entender o que é uma substância ácida e básica, respectivamente. Como apresentado no Gráfico 1, apenas 15,9\% dos alunos relacionaram de forma errada o $\mathrm{pH}$ de um ácido, afirmando ser uma substância que tem $\mathrm{pH}>7$, já a maioria $(84,1 \%)$ afirmou corretamente, atribuindo um ácido à um $\mathrm{pH}<7$. Todavia, como 
mostra o Gráfico 2, a turma ficou mais dividida na pergunta sobre o que eles entendiam por substância básica, onde $21,2 \%$ afirmou que uma base tem $\mathrm{pH}<7,10,5 \%$ afirmaram ser uma substância que pode ser consumida como alimento e 68,3\% afirmou corretamente que uma base tem $\mathrm{pH}>7$.

A maioria dos alunos da turma conseguiu relacionar o pH correto de uma substância básica e ácida. Porém, alguns alunos afirmaram que um ácido tem $\mathrm{pH}>7$ e a base tem $\mathrm{pH}<7$. Esse é um erro muito cometido por alunos do ensino fundamental e médio, pois, eles relacionam o aumento do $\mathrm{pH}$ com o aumento da acidez. Note que, uma parcela dos discentes também relacionaram as substâncias básicas ao consumo de alimentos, porém, diferentemente do que foi observado no início da apresentação da pesquisa, ao tratarmos dos ácidos isso não ocorreu. Assim, os alunos conseguiram quebrar o paradigma de que todo alimento ácido faz mal.

Gráfico 1: Resultados obtidos da primeira pergunta do questionário.

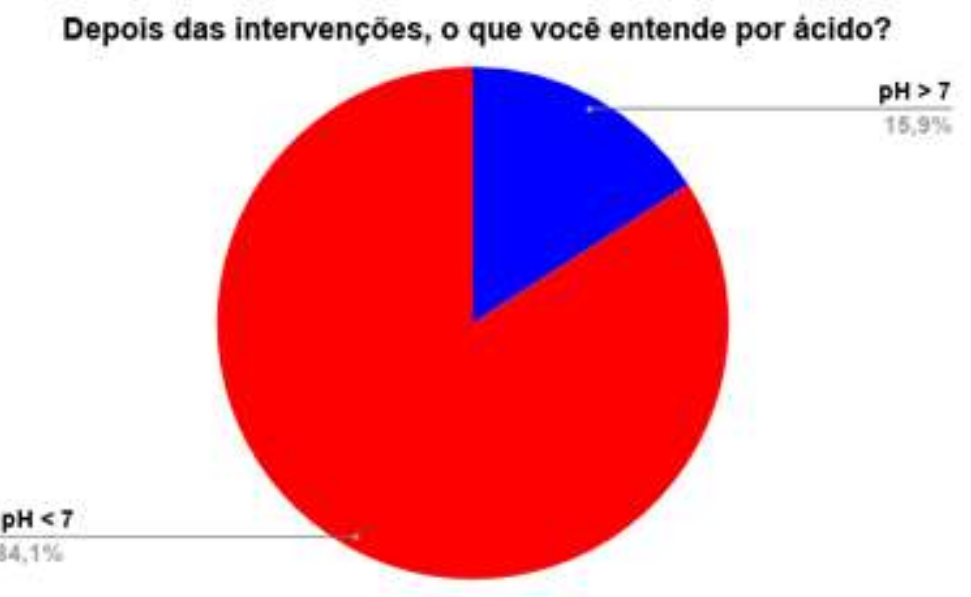

Fonte: Dados da pesquisa (2021).

Gráfico 2: Resultados obtidos da segunda pergunta do questionário.

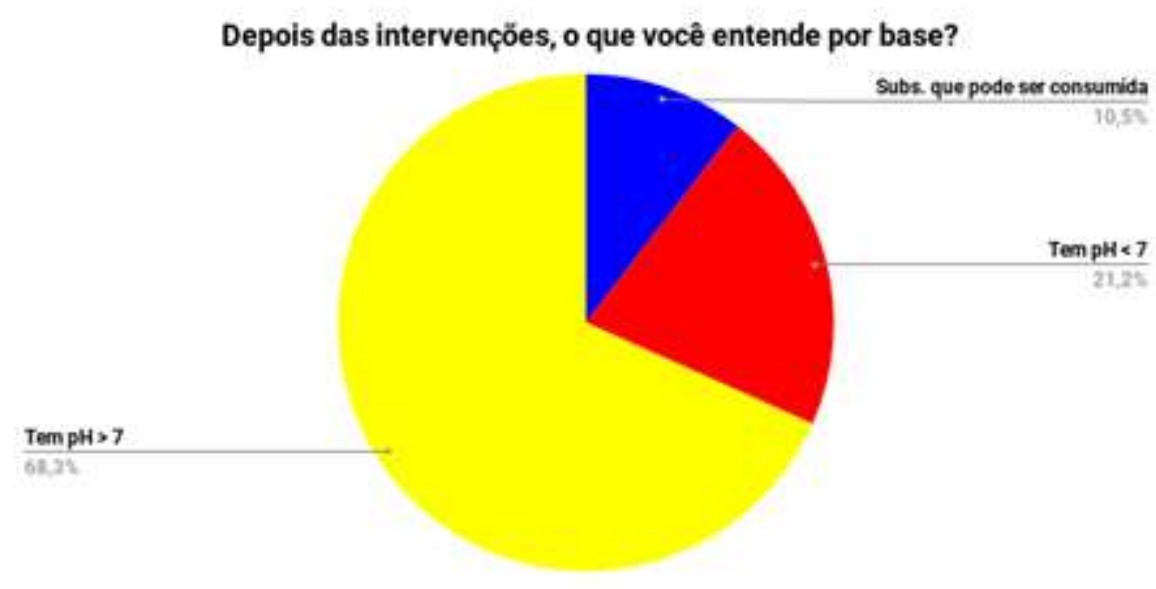

Fonte: Dados da pesquisa (2021).

A relação de "substâncias básicas" com "substâncias que podem ser consumidas" pode ter acontecido porque os discentes associaram a alcalinidade dos alimentos naturais saudáveis, como verduras, legumes e frutas, ao consumo de substâncias básicas. Em contrapartida, esse foi um erro conceitual ou de interpretação da pergunta feita, pois não podemos consumir as substâncias básicas, mas os alimentos, sim. Como relatado por Figueira (2010) os conceitos de bases são 
normalmente menos desenvolvidos por estudantes, tanto do ensino médio quanto do fundamental, do que o dos conceitos de ácidos.

Na terceira questão perguntou-se aos alunos se eles julgavam que todos os alimentos ácidos são prejudiciais à saúde. Como apresentado no Gráfico 3, onde, a maior parte dos discentes (84,2\%) afirmou que não, e apenas 15,8\% disseram que sim. Já na quarta questão perguntou-se aos alunos se eles achavam que todos os alimentos básicos prejudicam à saúde. Surpreendentemente, toda a turma respondeu que não, por isso não foi plotado nenhum gráfico para essa pergunta do questionário. Assim, os discentes conseguiram compreender corretamente o que foi abordado durante as intervenções sobre a importância de uma dieta equilibrada com alimentos básicos e ácidos.

Gráfico 3: Resultados obtidos da terceira pergunta do questionário.

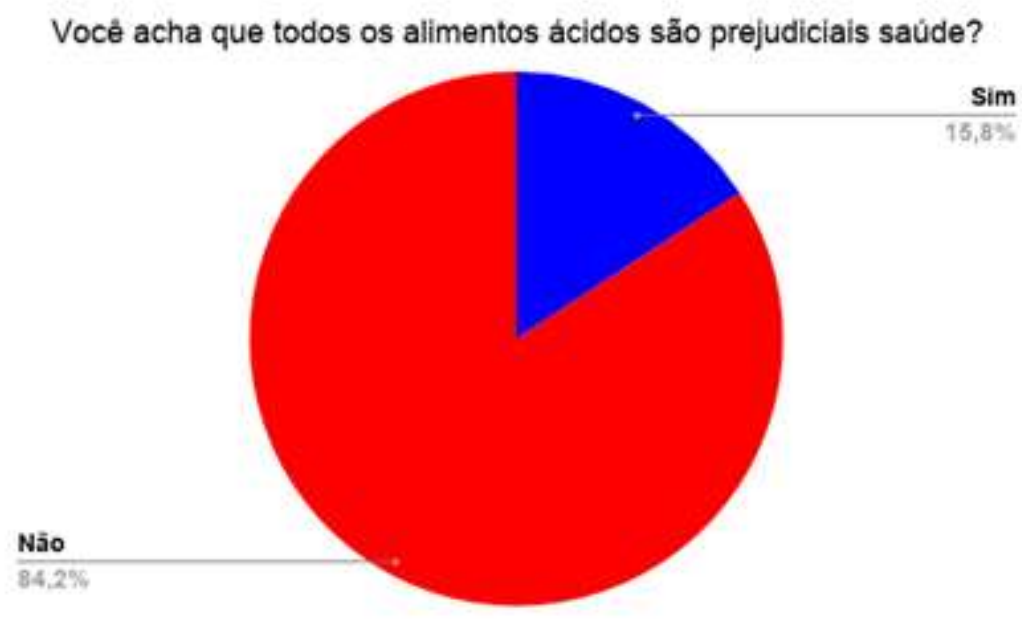

Fonte: Dados da pesquisa (2021).

Na quinta e última alternativa (Gráfico 4), perguntou-se aos alunos quais as substâncias ácidas eles tinham em casa. A maioria, 31,6\%, afirmou ter em casa o limão, 26,3\% disse ter laranja, 10,5\% afirmaram ter o arroz, mais 10,5\% disseram ter o feijão, 10,5\% relataram ter refrigerantes em casa, e apenas 10,5\% não responderam. A laranja e o limão são frutas ácidas, porém, os seus resíduos orgânicos que restaram no corpo após ingeri-los são alcalinos, tornando-os fortes alcalinizantes (Boavida, 2016). Portanto, os discentes conseguiram correlacionar bem tanto o pH dessas duas frutas quanto das demais substâncias citadas. 
Gráfico 4: Resultados obtidos da quinta pergunta do questionário.

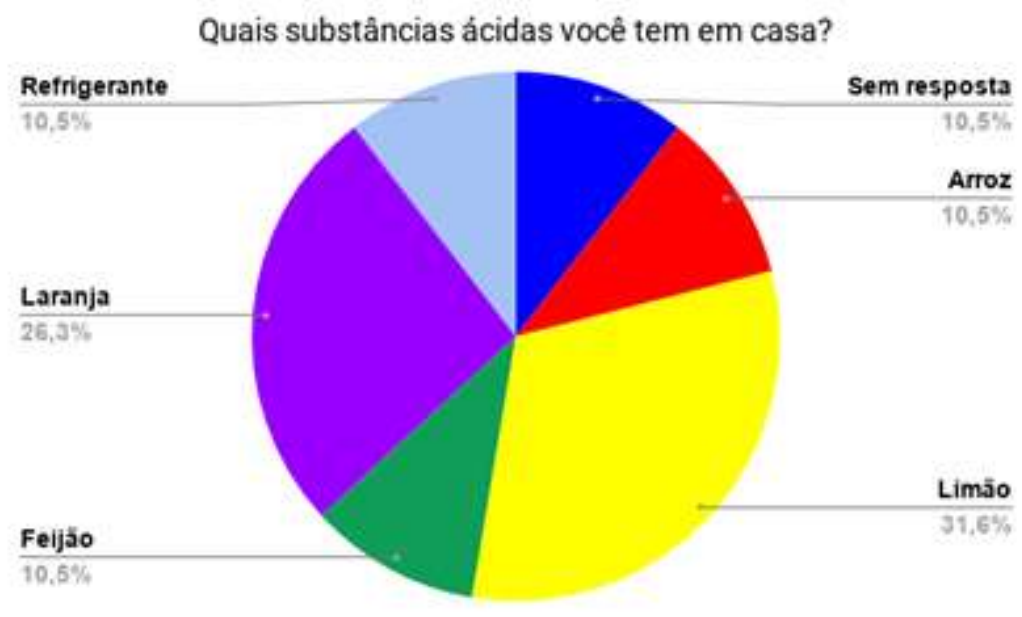

Fonte: Dados da pesquisa (2021).

Para finalizar a discussão e pesquisa, perguntou-se aos alunos se eles achavam necessário a realização de mais experimentos nas aulas de química. A maior parte da turma afirmou que seria muito mais interessante a implementação de mais atividades práticas e se entusiasmaram bastante na resposta. Da Silva et al. (2021) também observaram que, após as aulas experimentais, os alunos sentiram a necessidade de terem mais aulas práticas e conseguiram compreender melhor o conteúdo com essas aulas dinamizadas e contextualizadas.

Portanto, a avaliação quantitativa por meio do questionário foi de suma importância para analisarmos se os métodos utilizados (problematização, contextualização, aulas expositivas dialogadas) auxiliaram os alunos na compreensão dos conceitos de ácidos e bases e de pH. Diante dos dados obtidos, podemos observar que a maior parte da turma compreendeu bem o que foi retratado em sala de aula, conseguindo diferenciar alimentos e substâncias ácidas das básicas e sabendo diferenciar a faixa de $\mathrm{pH}$ desses compostos. De fato, às duas aulas expositivas dialogadas foram de suma importância para aquisição do conhecimento dos alunos. No entanto, percebeu-se um maior engajamento de toda a turma ao começar a discutir contextualizadamente os conceitos de ácidos e bases e, principalmente, como já esperado, durante a aula prática no laboratório.

\section{Considerações Finais}

Abordar conteúdos de química de forma contextualizada e problematizada é muito importante para auxiliar o processo de ensino-aprendizagem e promover uma aprendizagem mais significativa aos alunos. Além disso, os alunos sentem-se mais motivados e interessados em aprender os conteúdos de química tanto ao ter o uso aulas experimentais quanto ao promover uma relação dos assuntos com o dia a dia dos mesmos, pois, assim, eles encontram um sentido para utilizar tais conhecimentos em sua vida. Dessa forma, diante dos resultados obtidos neste trabalho pode-se perceber a importância de relacionar a química ao cotidiano dos discentes, pois isso gera uma visão mais ampla da teoria abordada e auxilia-os a encontrar soluções em situações do dia a dia. Percebeu-se também a importância de utilizar diferentes metodologias para abordar um conteúdo e aulas dinâmicas que possibilitem a interação aluno-aluno e aluno-professor.

Portanto, relacionar os conceitos de ácido-base com a química dos alimentos facilitou significativamente a dinâmica das aulas e a forma de abordar o conteúdo. Além disso, com essa contextualização os alunos mostraram-se muito mais interessados do que na primeira aula onde não ocorreu essa relação. A ida ao laboratório para realização de uma aula experimental que proporcionou a intercalação entre a prática e a teoria dos conceitos de ácido e base referentes aos alimentos também foi de suma importância para o satisfatório resultado desse artigo. Além disso, as metodologias elaboradas nesta 
investigação podem servir de auxílio para o docente no (ERE), visto que o experimento é de fácil desempenho podendo ser realizados pelos próprios alunos em suas residências com as instruções deixadas pelo professor, provocando nos discentes o interesse e gerando graus significativos no seu aprendizado.

Diante disso, a intervenção foi satisfatória e as propostas foram alcançadas com sucesso, sendo notório que os alunos compreenderam a importância do estudo sobre ácidos e bases e também se conscientizaram quanto a sua alimentação, quebrando vários paradigmas referentes ao consumo de alimentos.

\section{Referências}

Almeida, C. S., Yamaguchi, K. K. L., \& Souza, A. O. (2020). O uso de indicadores ácido-base naturais no ensino de Química: uma revisão. Research, Society and Development, 9(9), e175997243-e175997243.

Astolfi, J., \& Develay, M. (2011). A Didática das Ciências (12a ed). Papirus.

Ausubel, D. P., Novak, J. D., \& Hanesian, H. (1968). Educational psychology: A cognitive view. Rinehart and Winston,

Berton, S. B. R., Ferreira, M. P., Canesin, E. A.,Suzuki, R. M., Martins, A. F., Bonafé, E. G., \& Matsushita, M. (2020). Sequência didática para a promoção de estudo prático e multidisciplinar com materiais acessíveis. Química Nova, 43(5), 649-655.

Boavida, R.O Fator pH. Editorial Presença, 2016.

Bigolin, N. M., Silveira, S. R., Bertolini, C., de Almeida, I. C., Geller, M., Parreira, F. J., ... \& Macedo, R. T. (2020). Metodologias Ativas de Aprendizagem: um relato de experiência nas disciplinas de programação e estrutura de dados. Research, Society and Development, 9(1), e74911648-e74911648.

Brasil, L. D. D. (2006). Orientações curriculares para o ensino médio. Volume 2-Ciências da natureza, matemática e suas tecnologias. Secretaria de Educação Básica. Brasília: Ministério da Educação (MEC), Secretaria de Educação Básica.

Brasil. Ministério da Saúde. (2016). Desmistificando dúvidas sobre alimentação e nutrição: material de apoio para profissionais de saúde. Brasília: Ministério da Saúde, 164 p.

Brum, W. P. e da Silva, S. D. C. R. (2014). Os conhecimentos prévios dos estudantes como ponto referencial para o planejamento de aulas de matemática: Análise de uma atividade para o estudo de geometria esférica. Revista Eletrônica de Educação Matemática, 9(1), 43-57.

Capeletto, A. J. (1999). Biologia e Educação ambiental: Roteiros de trabalho. Ática.

Coelho, D. L., \& de Lima, S. M. (2020). As Contribuições Da Contextualização No Ensino De Química. In: Aninc-Anuário do Instituto de Natureza e Cultura, $3(1), 129-131$.

Costa, J. M. \& Pinheiro, N. A. M. (2013). O ensino por meio de temas-geradores: a educação pensada de forma contextualizada, problematizada e interdisciplinar. Imagens da Educação, 3(2), 37-44.

Da Silva, E. C. C., Barbosa, A. C., de Souza Fortes, A. Z., Ribeiro, D. C., Avelino, L. M., de Sousa, M. S., \& Sena, Y. W. B. (2021). Uma experiência da prática pedagógica em química por meio da experimentação. Brazilian Journal of Development, 7(6).

Da Silva, W. A., da Silva Andrade, R., \& Viana, K. D. S. L. (2019). Ácidos e bases: uma atividade experimental com a utilização do indicador natural no ensino de química. In: VI Congresso Internacional das Licenciaturas, COINTER - PVDL 2019, Recife, PE.

Del Pino, J. C., \& Frison, M. D. (2011). Química: um conhecimento científico para a formação do cidadão. Revista de Educação, Ciências e Matemática, 1(1).

Do Nascimento, L. F., \& Cavalcante, M. M. D. (2018). Abordagem quantitativa na pesquisa em educação: investigações no cotidiano escolar. Revista Tempos e Espaços em Educação, 11(25), 249-260.

Dos Santos, L. R., \& de Menezes, J. A. (2020). A experimentação no ensino de Química: principais abordagens, problemas e desafios. Revista Eletrônica Pesquiseduca, 12(26), 180-207.

Figueira, A. C. M., Oliveira, A. M., Salla, L. F., \& Rocha, J. B. T. (2009). Concepções alternativas de estudantes do ensino médio: ácidos e bases. VII Encontro Nacional de Pesquisa em Educação em Ciências, Florianópolis, Brasil.

Figueira, Â. C. M. (2010). Investigando as concepções dos estudantes do ensino fundamental ao superior sobre ácidos e bases. 2010. f. 77 (Doctoral dissertation, Dissertação de Mestrado. Universidade Federal de Santa Maria. Santa Maria, RS).

Freire, P. (1996). Pedagogia da Autonomia: Saberes Necessários à Prática Educativa (25a ed). Paz e Terra.

Gava, A. J., da Silva, C. A. B., \& Frias, J. R. G. (2009). Tecnologia de alimentos. NBL Editora.

Gonçalves, T. M. (2021). Uma proposta de aula experimental no ensino a distância: Identificando proteínas em alimentos do cotidiano na disciplina de Bioquímica. Research, Society and Development, 10(4), e52110414441-e52110414441.

Guimarães, C. C. (2009). Experimentação no ensino de química: caminhos e descaminhos rumo à aprendizagem significativa. Química nova na escola, 31(3), $198-202$. 
Research, Society and Development, v. 11, n. 1, e2521118057, 2022

(CC BY 4.0) | ISSN 2525-3409 | DOI: http://dx.doi.org/10.33448/rsd-v11i1.18057

Hodges, C., Moore, S., Lockee, B., Trust, T., \& Bond, A. (2020). The difference between emergency remote teaching and online learning. Educause review, 27, 1-12.

Liell, C. C., Bayer, A., \& Ledur, J. R. (2020). Aprendizagem significativa de conceitos básicos de cinemática no ensino fundamental. Revista de educação, ciências e matemática, 10(1).

Lima, A.M.; Santos,G.L.; Nascimento, G.S.D \& Florentino, B.G.M. (2021). Contextualização no Ensino de Química Orgânica: A Química dos Perfumes como Tema Gerador. In: Vivências didáticas: Metodologias aplicadas em ensino e aprendizagem, 3.

Lima, J. O. G., \& Barbosa, L. K. A. (2015). O ensino de química na concepção dos alunos do ensino fundamental: algumas reflexões. Revista Científica do Departamento de Química Exatas, 6, 33-48.

Maldaner, O. A. (2000). A Formação Inicial e Continuada de Professores de Química: Professores/pesquisadores. Editora Unijuí.

Miranda, A. C. G., Pazinato, M. S., \& Braibante, M. E. F. (2017). Temas geradores através de uma abordagem temática freireana: contribuições para o ensino de ciências. Revista de Educação, Ciências e Matemática, 7(3).

Nelson, D. L., Cox, M. M., \& Lehninger, A. L. (2005). Principles of biochemistry (4a ed). WH Freeman and Company, 1(1.1), 2.

Queiroz, D. L., Martins, A. C., \& Fernandes, C. C. (2019). Determinação de pH: utilização de materiais alternativos para ensino de química. Scientia Naturalis, 1(1).

Ribeiro, E. P., \& Seravalli, E. A. (2007). Química de alimentos (2a ed). Editora Blucher.

Santos, J. C. F. (2008). Aprendizagem significativa: modalidades de aprendizagem e o papel do professor Mediação.

Santos, J. C. F. (2011). Aprendizagem significativa: modalidades de aprendizagem e o papel do professor (4a ed). Mediação.

Santos, W. L. P. D., \& Schnetzler, R. P. (2003). Educação em química: compromisso com a cidadania (3a ed). Editora Unijuí.

Santos, W. L. P. D. (2007). Educação científica na perspectiva de letramento como prática social: funções, princípios e desafios. Revista brasileira de educação, 12(36), 474-492.

Silva, J. C., Martins, M. C., \& Silva, R. V. (2020). Elaboração de uma sequência didática no ensino de Química estruturada em uma metodologia ativa com tema gerador: o café. Research, Society and Development, 9(9), e459997253-e459997253.

Tozoni-Reis, M. F. D. C. (2006). Temas ambientais como" temas geradores": contribuições para uma metodologia educativa ambiental crítica, transformadora e emancipatória. Educar em revista, 93-110.

Wartha, E. J., Silva, E. D., \& Bejarano, N. R. R. (2013). Cotidiano e contextualização no ensino de Química. Química nova na escola, 35(2), 84-91.

Zanon, D. A. V., \& De Freitas, D. (2007). A aula de ciências nas séries iniciais do ensino fundamental: ações que favorecem a sua aprendizagem. Ciências \& Cognição, 10. 